\title{
Mirror image as a reinforcer in Siamese Fighting Fish: A repetition with additional controls'
}

\author{
STEPHEN R. GOLDSTEIN
}

UNIVERSITY OF ALBERTA

Thompson (1963) has demonstrated that Siamese Fighting Fish (Betta splendens) will learn to swim through a ring if this response is immediately followed by mirror-image presentation. The present study successfully repeats this demonstration and shows, through the use of yoked-control (mirror-image noncontingent) and operant-control (mirror-image absent) groups, that the effect cannot be accounted for by an enhancement of general activity, though such a factor appears to exert a small, though not insignificant, effect on operant responding.

As part of a series of recent studies with Siamese Fighting Fish (Betta splendens), Thompson (1963) and Thompson \& Sturm (1965) have used instrumental conditioning and extinction procedures to demonstrate that stimuli capable of evoking unlearned aggressive behavior have reinforcement properties. More recently, Beanninger (1966) has argued that the extinction data reported by Thompson (1963) could be attributed to habituation. However, such a contention fails to take account of the fact that habituation is definedand occurs-as a result of repeated presentation of a constant stimulus (Humphrey, 1933) whereas extinction is operationally defined as a procedure specifying absence of such stimulation (Ferster \& Skinner, 1957).

A more serious problem involves the acquisition phase of Thompson's study. Here the operant response consisted of swimming through a ring with a 3 in. diameter, for which $S$ was reinforced by a 20-sec. mirror presentation. Such an operant, however, raises the possibility that mirror-maintained responding may be confounded with variables not directly involved in instrumental learning. For example, in describing the fighting behavior of Bettas, reference is usually made to the fact that opponents frequently "circle" each other in a highly ritualistic fashion prior to combat (Evans et al, 1958). Moreover, this same effect can be observed by placing a mirror before a male Betta, the reinforcement procedure used by Thompson. Therefore, because of the relatively wide diameter of the operandum and its proximity to the area of reinforcement, the possibility exists that an undetermined portion of responding attributed to conditioning may in fact be the result of "circling" engendered by the activating effect of mirror image.

The purpose of this study is to determine, by a yoked-control (YC) design, the extent to which heightened activity, produced by the supposedly reinforcing stimulus, can account for operant responding. This is made possible by the fact that in the YC design reinforcements are presented independently of ongoing behavior, minimizing the possible acquisition of a specific response and leaving the heightened activity variable as the major source of response variance. In addition, an operant-control (OC) group was employed to control for the possibility that a propensity for ring-swimming might increase as a function of time in the tank.

Method

The Ss were 12 adult male B. splendens, all approximately $8 \mathrm{mo}$. old. Each $\mathrm{S}$ was fed once daily on a diet of Tetra-Min and live white worms (Enchytraeus albinus).

The yoking apparatus consisted of two $2-1 / 2$ gal. aquaria equipped with a photocell system, wired in series, the light of which passed through a vertical stem of a circular ring device 3 in. in diameter. A 100-W bulb was located directly behind a two-way mirror, 4 in. $\times 8$ in., fixed to the rear glass of each tank. In the normal position the bulb was on and the mirror thus acted as glass. With the bulb off, a true mirror effect was produced. Responses were recorded on a triple channel event recorder (Davis Scientific) and electromagnetic counters.

The operant control apparatus consisted of four independently operated units set up identically to the YC equipment but lacking the two-way mirrors. Responses for these units were recorded on separate event counters.

Yoking procedure Eight Ss were randomly divided into a response contingent $(\mathrm{RC})$ and $\mathrm{YC}$ groups. Ss were run in pairs $24 \mathrm{hr}$./day for 14 consecutive days. This period consisted of a 2-day operant, a 10-day conditioning, and a 2-day extinction phase.

During the operant phase responses emitted by either $S$ were independently recorded, but produced no systematic stimulus change in either S's environment.

During conditioning, $S$ in the RC group could produce a 20-sec. mirror presentation for himself and the YC by swimming through the ring. Responses emitted by the YC, however, could not actuate the mirrors.

In extinction, responses by either $S$ were ineffective in procuring mirror presentation.

Operant procedure One of four Ss was assigned at random to a separate aquarium and remained there $24 \mathrm{hr} . /$ day for 14 consecutive days. Ring swimming produced no systematic stimulus change in S's environment throughout the 14 days.

\section{Results and Discussion}

Figure 1 shows the results of this study. It is obvious that during the conditioning phase, where rein- 
PERFORMANCE CURVES

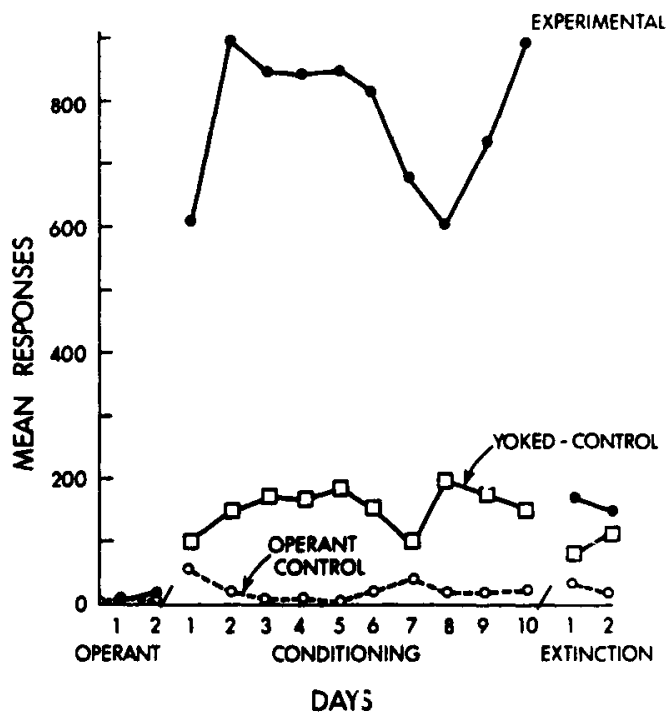

Fig. 1. Mean daily performance of three groups for which mirror presentation was response-contingent (Experimental), noncontingent (Yoked-Control), and absent (Operant-Control).

forcement is response-contingent, that average daily rate of responding is quite high. This effect-using Duncan's New Multiple Range Test-is significantly above $Y C$ rates $\left(R_{3}=105.29, R C-Y C=624.15\right.$, $\mathrm{df}=27$, $p<.01)$ and $O C$ rates $\left(R_{2}=100.96, R C-O C=745.72\right.$, $\mathrm{df}=27, \mathrm{p}<.01$ ) for the 10 days. The $\mathrm{YC}$ group is also significantly above the OC group $\left(R_{2}=100.96, Y C-O C\right.$ $=121.57$, $\mathrm{df}=27, \mathrm{p}<.01$ ) and, on the average, represents about $19 \%$ of RC responding.

As the YC design was employed here, it is possible that: (a) the YC may have been occasionally reinforced for ring-swimming, thus producing an inflated eatimate of activity, and (b) the YC may not have responded to all mirror presentations. With regard to the first point, the probability that both Ss are responding at the same time-at any given time during a $24 \mathrm{hr}$. day - is quite small. Therefore, the high VR schedule engendered by such an unlikely event would presumably not be sufficient to sustain responding to any significant extent. Thus Thompson (1964) reports a breakdown of mirror-maintained behavior in fighting cocks at FR 75. If the second point is true, the YC data presented would represent a conservative estimate of ring-swimming behavior attributable to increased activity.

The data, then, clearly replicate the finding that Siamese Fighting Fish will learn to swim through a ring if mirror-image presentation is made contingent upon this response. Furthermore, it is evident that increasing activity was produced by presenting mirrorimage independently of behavior, in that under these conditions response rate was significantly higher than the baseline operant rate. This in turn suggests the possibility (since YC reinforcements were situationally dependent upon $\mathrm{RC}$ reinforcements) that the RC curve may give a somewhat inflated estimate of performance attributable to learning.

\section{References}

Beanninger, $\mathbf{R}$. Waning of aggressive motivation in Betta splendens. Psychon. Sci., 1966, 4, 241-242.

Evans, L. T., Abramson, H. A., \& Fremont-Smith, N. Lysergic acid diethylamide (LSD-25): XXVI Effect on social order of the fighting fish, Betta splendens. J. Psychol., 1958, 45, 263-273.

Ferster, C. B., \& Skinner, B. F. Schedules of reinforce ment. New York: Appleton-Century-Crofts, 1957.

Humphrey, G. The nature of learning in its relation to the living system. London: Routledge, 1933.

Thompson, T. Visual reinforcement in Siamese Fighting Fish. Science, 1963, 141, 55-57.

Thompson, T. Visual reinforcement in Fighting Cocks. J. exp. Anal. Behav., 1964, 7, 45-49.

Thompson, T., \& Sturm, T. Visual-reinforcer color and operant behavior in Siamese Fighting Fish. J. exp. Anal. Behav.. 1965, 8, 341-346.

\section{Note}

1. The helpful comments and suggestions of Drs. W. Runquist, $R$. Stretch, and T. Thompson, regarding various drafts of this paper, and the help of Mr. P. de Groot with the design and construction of equipment, is gratefully acknowledged. 